\title{
Methods of Testing a Large Number of Motives for Vocational Guidance
}

\author{
Andrey Polozov", Liudmila Brekhova \\ Department of Physical Education, Ural Federal University, Ekaterinburg, Russia \\ Email address: \\ a.a.polozov@mail.ru (A. Polozov), ludmilaobogrelova@mail.ru (L. Brekhova) \\ ${ }^{*}$ Corresponding author
}

\section{To cite this article:}

Andrey Polozov, Lyudmila Brekhova. Methods of Testing a Large Number of Motives for Vocational Guidance. Education Journal. Vol. 8, No. 5, 2019, pp. 175-184. doi: 10.11648/j.edu.20190805.12

Received: April 16, 2019; Accepted: May 29, 2019; Published: August 10, 2019

\begin{abstract}
There are a huge number of motives and 60 theories explaining them. However, it is not possible to compare the significance of various motives for an individual - there may be too many motives. And accordingly, the issues related to their testing becomes a very large number. Therefore, conclusions have to be made on the example of a very small sample of the most sought-after motifs. A technique is proposed that allows one to obtain the results of comparing a large number of motives with a relatively small number of questions asked. The test consists of 47 questions with pairwise opposition of 11 different motives. The result is obtained by solving a system of linear equations. As a result of the work done, we can predict the behavior of anyone tested, say what he chooses in a given life situation, if it can be interpreted as a confrontation between two motives. To assess the significance of the motive, a rating system was used, in which the motive rating was the higher, the more there was a choice in its favor in pairwise comparison with all other motives. The difference in the ratings of the two motives is linearly related to the probability of choosing both motives. This allows you to create a rating hierarchy of the motives of the subject without direct testing based on his decisions in everyday situations. The indicated method overcomes the well-known problem of the avalanche-like growth of the number of test questions with a large number of motives and forms the probabilistic value of the evaluation of the choice of one of the alternatives. A small number of questions allows you to significantly increase the value of the retest reliability of the answers of the subjects.
\end{abstract}

Keywords: Motives, Values, Motive Importance, Selection Probability

\section{Introduction}

When conducting career-oriented testing for a long time, we could not solve the problem. The test used several different criteria for compliance with the future profession. There are young people who are interested in a well-paid job. Others appreciate the possibility of achieving a socially significant result. There are people who appreciate the opportunity to realize their potential. The values of these and other criteria are established during the test. How to combine all these estimates into one result? The value of the overall assessment of this specialty for the applicant allows you to place all the specialties at the university for a given applicant in descending order of their importance. But how to determine the personal significance of the indicator that we have chosen for each? We cannot use coefficients that are universal for all. They must be defined individually for each. We have formed an algorithm that, according to the test results, allows us to get a personal level of significance for each of the estimates obtained.

The Concept of Motive. A variety of psychological phenomena were called motives. These are intentions, views, ideas, feelings, and experiences (L. I. Bozhovich) [1]; needs, desires, impulses, inclinations (H. Heckhausen) [2]; desires, wishes, habits, thoughts, sense of duty (P.A. Rudik) [3]; moral and political attitudes and thoughts (G. A. Kovalev) [4]; mental processes, states, and properties of the personality $(K$. K. Platonov) [5]; objects of the outer world (A. N. Leontiev) [6]; attitudes (A. Maslow) [7]; existence conditions (K. Viljunas) [8]; motivations, on which focused actions depend ( $V$. S. Merlin) [1], consideration, according to which a subject should act (J. Godefroid) [9]. According to Wikipedia, motivation is a desire to perform an action; a psychophysiological process governing human behaviour, setting its direction, arrangement, activity, and stability; the 
human ability to actively satisfy the person's needs.

There are as many different reasons as there are meaningful equivalent classes of "individual-environment" relationships. [2].

Richard M. Ryan divides motives into autonomous intrinsic and variable extrinsic ones [10]. David McClelland describes methods of measuring motives: achievement, power, affiliation and avoidance - reviewing and evaluating research on how these motive systems affect behaviour [11].

The majority of techniques for defining motivation determine only two motives: achievement of success and avoidance of failures. Only motive and motivation to achieve success have been mainly studied both abroad and in our country in terms of ontogenetic development. Much less attention has been paid to theoretical and experimental research of motives and motivation of affiliation, motives to help people, motivation for power, knowledge, independence, and aesthetic needs. As far as motive and motivation for power are concerned, the vast majority of research related to this issue is focused not on the genetic aspect of motivation studies, but on the motivation in relation to the issues of administration and management, first and foremost, with regard to production collectives (psychologists were mainly interested in the issues of subjects' interaction within the "manager-subordinate" system). The motivational hierarchy of all known tests looks incomplete.

The first motivation determining technique, the Thematic Apperception Test (TAT), was developed by Henry Murray and his colleagues at the Harvard Psychological Clinic during the late 1930s. D. McClelland and J. Atkinson made a great contribution to the development of special tools aimed at measuring particular motives [11]. The stimulus material of the technique involved four pictures from the standard TAT set. Later the number of such pictures increased to six. However, their approach often mixed up two different motivational trends - "hope for success" and "fear of failure" - when changing the achievement motive. The advantage of HTAT by $\mathrm{H}$. Heckhausen is the possibility of quantitative qualification of "achieving success" and "avoiding failure" motives, ranking responses of subjects, and the possibility of standard assessment of the results. The research related to HTAT and its modifications, which were carried out by M. Sh. Magomed-Eminov [12, 13], B. G. Rebzuev [14], etc., are well-known in the CIS countries (see also Achievement-Motive Grid).

Afterwards, "achieving success" and "avoiding failure" scales began to be studied in the following tests:

1. "achievement motivation" test by A. Mehrabian, where the respondents use a 7-point scale to assess statements related to negative and positive motivation.

2. test of motivation of success and fear of failure, questionnaire by A. A. Rean [15],

3. techniques by $T$. Ehlers for the diagnostics of personality's motivation for success achievement and failure avoidance consisting of 41 statements. Despite the fact that this scale is declared as defining the achievement of success, there are questions concerning material needs, for example - "there are few things in life, which are more important than money" - and questions concerning the need of being approved by the society "I know that my colleagues consider me a competent person".

Since 1960s, the interest in the measuring of values and values-based orientations has begun to grow [16]. A value is any "object" that is essential to a person. Such technique type may be exemplified with a Rokeach Value Survey (RVS), a values classification instrument developed by $\mathrm{M}$. Rokeach, which is widely used in the national psychodiagnostic practice. A. G. Goshtautas, N. A. Semenov, and V. A. Yadov adapted it to the national selection of adults. The author of this technique distinguishes between two types of values:

1. terminal values, which are beliefs that desirable end-states of a person's existence are worth to be sought for;

2. instrumental values, which are beliefs that some mode of behaviour or property of the personality is preferable in any situation.

This classification corresponds to the classification of values typical for the Russian psychological science, where values are classified into values as goals and values as means. The respondent independently should put two lists of values (each of them containing 18 items) in order of priority to them. The examples of terminal values (list A) are the following: an exciting life, life wisdom, health, an interesting job, beauty of nature and the arts, etc. The examples of instrumental values (list B) are the following: neatness and tidiness, politeness, ambitions, vivaciousness, diligence, etc. A modified version of the Rokeach Value Survey, suggested by B. S. Kruglov, is used in domestic practice. This version includes reduced lists of values (16 instead of 18), and the respondents should assess each value on a 5-point scale (from 1 to 5) instead of ranking them [17].

In 1991 I. G. Senin offered a questionnaire of terminal values containing 80 statements [15]. The technique allows to assess an overall degree of each of eight terminal values: a person's own prestige, high material affluence, creativity, active social contacts, self-development, achievements, spiritual fulfilment, preservation of their own identity. Assessment is also made of the person's representation in professional life, training and education, family and social life, and their hobbies. There is data about the satisfactory reliability of this questionnaire (test-retest reliability factor 0.52-0.77; split-half reliability factor - 0.71-0.87), and about its construct and criterion validity. V. F. Sopov and L. V. Karpushina afterwards refined on the technique by I. G. Senin by creating a "Morphological Test of Life Values" consisting of 112 statements. This technique was called "Morphological Test of Life Values" due to goals and objectives of the research aimed at the determination of motivational and axiological structure of a personality.

A widely known technique is a "Method of Studying of Personality Motivational Sphere" developed by V. E. Milman. It has the following scales: life sustenance, comfort, communication, total activity, creativity, social benefit. This 
classification does not make it clear what total activity is, and what well-known motive it can be related to. The technique is presented as statements to be assessed according to a given scale.

There emerged also the so-called "European values". Article 2 (Values of the Union) of the Treaty on European Union reads: "The Union is founded on the values of respect for human dignity, freedom, democracy, equality, the rule of law and respect for human rights, including the rights of persons belonging to minorities. These values are common to the Member States in a society in which pluralism, non-discrimination, tolerance, justice, solidarity and equality between women and men prevail".

The weakest links of all techniques studying motivation are the following:

1. scoring system: a points-based system is used. A person gets a certain score for each motive. Here the motives do not contradict each other, as it happens in real life. In this case the respondent can increase their ratings on all scales in multi-component techniques for motivation determination.

2. desire to give not a real assessment but the one, which would be approved by others

3. absence of a real-life choice situation

The purpose of the research is to create a technique for the assessment of motivation strength out of a large number of motives being compared and the lowest possible number of test questions.

The object of the research is a hierarchy of the respondent's motives.

The subject of the research is a rating technology for testing motivational sphere.

The hypothesis of the research is the following - studying motivational structure of a personality may allow to predict a person's behaviour in the situation of choice, when a lot of motives may occur.

\section{Method}

\subsection{Creating a Motivational Hierarchy Rating Assessment Technique}

It is necessary to take a number of common life situations with an approximately equivalent choice of behavioural alternatives. The following question should be answered in order to create such test: What is included in the motives of social behaviour?

The first 11 motives do not correlate with one another, whereas the subsequent ones have mutual correlations with other motives or constitute a synthesis of them. The need for self-improvement is very similar to the need for self-actualisation, that is, to self-fulfilment. The hedonistic need (need for comfort, and serenity), Z. Freud's "pleasure principle" will correlate with the physical and aesthetic needs, and the need for communication, i.e. with everything that ensures comfort [18]. A corporate motive correlates with many other selected motives, such as achievement motive, humanistic motive, and motive of avoiding failures. The need for self-affirmation distinguished by E. Fromm correlates with the motives of achievement, success, and self-fulfilment (Ilyin, 2004).

Table 1. Needs distinguished by the authors of various motivation theories.

\begin{tabular}{|c|c|c|c|c|c|c|c|c|c|c|}
\hline Motives Authors & H. Murray & A. Maslow & $\begin{array}{l}\text { Mc } \\
\text { Clelland }\end{array}$ & $\begin{array}{l}\text { C. } \\
\text { Alderfer }\end{array}$ & Herzberg & $\begin{array}{l}\text { E. } \\
\text { Fromm }\end{array}$ & $\begin{array}{l}\text { J. } \\
\text { Atkinson }\end{array}$ & $\begin{array}{l}\text { H. } \\
\text { Heckhausen }\end{array}$ & $\begin{array}{l}\text { B. I. } \\
\text { Dodonov }\end{array}$ & $\begin{array}{l}\text { V. I. } \\
\text { Gerchikov }\end{array}$ \\
\hline Communication & \# & \# & \# & \# & & \# & & \# & \# & \\
\hline Of power & \# & & \# & & & & & \# & & \# \\
\hline Of independence. & \# & & & & \# & & & & & \\
\hline Of cognition & \# & \# & & & \# & & & & \# & \\
\hline Humanistic & \# & & & & & \# & & & \# & \\
\hline Material & & \# & & \# & & & & & \# & \# \\
\hline Of self-fulfilment & & \# & & \# & \# & \# & & & & \# \\
\hline Achievement & \# & & \# & & \# & & \# & \# & \# & \\
\hline Aesthetic & & \# & & & & \# & & & \# & \\
\hline Corporate & & & & & & & & & & \# \\
\hline Self-improvement & & \# & & & & & & & & \\
\hline Hedonistic & & & & & & & & & \# & \\
\hline Self-affirmation & & & & & & \# & & & & \\
\hline
\end{tabular}

The table does not include all the needs outlined in Frederick Herzberg's theory of motivation [17]:

1. the need for promotion, (professional growth), which summarizes a large group of other needs such as needs for power, achievement, success, material need, and need for self-fulfilment.

2. the need for recognition and approval of results, which can be interpreted as a combination of corporate motive, and motives for achievement and avoiding failures.
3. the need for a high degree of responsibility for a situation combines the needs for achievement, power, independence, and a corporate need.

Hence, 11 mutually non-correlated motives were chosen for our experiment: [19]

i. Motive for cognition - a desire to learn new principles, inducement to making efforts by the process and content of the activity rather than by external factors. (Maslow (1954), Murray (1938)). 
ii. Negative motive - inducements caused by the awareness of some troubles and inconveniences that may arise in the event of non-fulfilling of an activity, avoidance of failures and accusations. (H. Murray (1938), J. Atkinson (1964), D. McClelland (1971)).

iii. Affiliative communication is a type of communication that brings satisfaction, fascinates, and is liked by a person. The need for affiliation distinguished by $\mathrm{H}$. Murray (1938), the need for belongingness and love by A. Maslow (1954), the need for involvement by $\mathrm{D}$. McClelland (1971), human connections by E. Fromm, the need for affiliation by $\mathrm{H}$. Heckhausen

iv. Material motive is a motive of financial security. Acquisitive need (need for accumulation, acquisition) [B. I. Dodonov, 1978], instrumental need [V. I. Gerchikov, 2003].

v. Success is an achievement highly appreciated by the society. The motive is related to self-esteem, ambition, and self-respect. A person is trying to prove to people that they are worth something and seek to obtain a high social status. The desire for prestige by H. Murray (1938), the need for recognition of by A. Maslow (1954) [Cit. ex: Ilyin, 2004]. The glorious need (need for self-worth recognition) [B. I. Dodonov, 1978].

vi. Motive of power - control, dominance at the level of society, the subject's desire to influence people, one of the main driving forces of human actions; this is the desire to take a leading position in the group (or team), attempt to manage people, to determine and to regulate their actions. Dominance by H. Murray, (1938), motive of power by A. Adler (1922), D. McClelland (1971) [Cit. ex.: Ilyin, 2004], imperious resolution [V. I. Gerchikov, 2003].

vii.Humanistic - the ability to consider the interests of other people, the motive of duty and responsibility to society, group, or certain people. The need for nurturance by $\mathrm{H}$. Murray (1938), warm feelings towards a living being and the need for response by E. Fromm [Cit. ex.: Ilyin, 2004], the altruistic need (the need to make selfless actions) [B. I. Dodonov, 1978].

viii. Self-fulfilment - the implementation of the person's potential, the need for self-determination and self-improvement. The desire to completely implement the person's abilities, and the person's desire of to feel their own competence, according to A. Maslow (1954) [Cit. ex.: Ilyin, 2004].

ix. Aesthetic - the strive for harmony, and aesthetic perfection, according to A. Maslow (1954) [Cit. ex.: Ilyin, 2004], the need for the beautiful [B. I. Dodonov 1978].

$\mathrm{x}$. Motive of independence - freedom in making decisions, according to H. Murray (1938) [Cit. ex.: Ilyin, 2004]

xi. Motive of achievement is the desire to achieve good results; it is manifested in the choice of complex tasks and the desire to fulfil them, according to H. Murray (1938), achievement of success by J. Atkinson (1964), and D. McCleland (1971) [Cit. ex.: Ilyin, 2004], praxis need (the need for the impact of efforts) [B. I. Dodonov, 1978], professional need [V. I. Gerchikov, 2003].
Once we have selected 11 motives, there arose a question of choosing the method of comparing them. We are interested not in the motives as such, but in the choice people guided by them make in real life situations. For this purpose we need a test, in which the motives will "oppose" each other, just as in real life. A kind of "competition of motives" needs to be held in order to determine the actual motive hierarchy (the superiority of one motive over another). In this competition each motive will "face" other motives. A special test was created for this purpose. This test contains situations of motivational choice, where motives in both options oppose each other. In order to create such a test, it is necessary to take a number of common life situations with an approximately equivalent choice of behavioural alternatives. For example: "Your family already has one child. You would like to have one more, but it will bring about the worsening of your financial situation. Will you stop at having just one child?" It is clear that this tough choice happens in the life of every family, and any choice will not be an easy one. Here the humanistic motive opposes the material one. We have analysed artistic works, films, moments of life experienced or to be experienced by every person, and very frequently "borrowed" the situations of choice from them. However, to create such situational questions was not an easy task at all.

\subsection{Adjustment of the Technique}

The total number of tested students was 256 .

1. Motives with high mutual correlations were discarded at the stage of selecting motives. The mutual correlations of responses based on the remaining 11 motives did not exceed 0.5 . The motives of power and success show the biggest correlation factor among the remaining 11 motives.

2. Equivalence of the choice options. The questions, in which one answer was more than by 20 per cent more preferable than another, were discarded. We considered such alternatives as unequal.

3. The students were offered to indicate the opposing motives in each question on the basis of the list of motives and their definitions. In total, about 10 per cent of the questions, in which over 20 per cent of the students made a mistake indicating the opposing motives, were replaced.

4. Retesting was to take place in a month. On average, after a month the students changed their opinions in 14 per cent of cases. This is a relatively small number; however, it was unevenly distributed among 47 questions. Five questions, the answers to which were most often changed in a month time, were replaced. After that the retesting revealed only 8 per cent of questions, in which students changed their opinions. Further investigation of this question did not lead to a reduction of the mentioned number and was considered as the reached limit.

5. During the whole period of working with the test, we tried to find questions and answer options that were the most emotionally meaningful for the respondents.

47 questions, in which there was a clear opposition of two motives, were selected. There were 8-9 questions focused on each motive. 


\subsection{Rating Motivation Test}

Choose one alternative from the suggested two. Consider your decision thoroughly - what would you do in more than 50 per cent of similar cases? Do not "complete" the situation with your own thoughts. All other factors are the same in both cases.

1. What would you prefer: a broad circle of contacts and a steady job as a manager (1) or a participation in an innovative project (2) accompanied by a loss of a certain part of regular communication ties? 2

2. In order to succeed, will you opt for a short-term coaching from a famous, successful expert (1) or from an academic employee (2), who will set out all known facts in details? 1

3. You are invited to a friend's birthday party, where quite a few of your friends are going to be. However, it is necessary for you to stay overtime for a good extra pay. Will you go to the birthday party?

Yes

No

4. Would you rather go to the competition not covered by mass media and get a financial reward than to the competition with extensive media coverage but without getting any financial reward?

Yes

No

5. You have one inefficient employee under your supervision, and a number of negative consequences of this fact. Would you rather "drag" them further putting the performance of the set task at risk, than replace them with someone else?

Yes

No

6. Would you rather invest your money into a new bank (1) at a higher interest rate, or leave it in the same good old (2) bank at a usual interest rate? 1

2

7. Would you remain a Chief Executive Officer of the local branch of a company with the relative independence in decision-making (1) or would you agree to a higher but subordinate position in a more well-known company, without the usual autonomy (2) ? Would you sacrifice your independence for a more successful career?

2

8. Your family expects you to go to college in accordance with the family tradition, but you are more interested in another major. Would you act against your parents' will and family traditions for the sake of your self-fulfilment? Yes

No

9. Your family already has one child. You would like to have one more, but it will bring about the worsening of your financial situation. Will you stop at having just one child?

Yes

No

10. Would you rather remain an ordinary manager at a company with relative freedom and independence in decision-making (1) or prefer a position, which is more relevant to your aptitudes, but is under close supervision of an immediate superior (2)?

11. What is more important for you when writing a thesis: to finish it faster and take a higher position in the government agencies (1) or (2) its scientific validity, and citation? 1

2

12. Would you prefer a job with a higher level of payment with the usual range of responsibilities (1), or agree to a less paid job, which is cognitively more meaningful (2)? 1

13. Would you at your own responsibility establish relations and communicate with a person, who has a bad reputation? Yes No

14. Would you agree to leave everything behind and go abroad to implement your company's project? $\mathrm{Ye}$

No

15. What is best for you: (1) to agree to a higher management position with the responsibilities that are unusual for you or (2) to be in a lower position, but perform the job you are comfortable with?

2

16. Would you agree to take a managerial position among colleagues, many of whom in this case will treat you unkindly? Yes 
17. Do you happen to be afraid of wearing new beautiful clothes fearing that your friends' reaction to that might be a negative one?

Yes

18. Do you support the decision of Olga Zaitseva, a famous biathlete, who could easily win a medal in the next Olympics, but decided to finish her career in order to focus more on her son?

Yes

19. Who is best: a tutor, (1) who is irritable, able to shout at you or even expel you, but who is more qualified and knowledgeable, and has a lot to learn from, or (2) who is calm, kind, and has an intermediate level of knowledge?

1

20. You have nice, good neighbours with children, and a low level of income. They ask you to be a guarantor for a mortgage. Would you agree?

Yes

No

21. Your institution becomes responsible for implementing an interesting project by a certain date. For this purpose you will have to regularly work on weekends or overtime. Would you try to change jobs, if it becomes a common practice?

Yes

No

22. What is appropriate for you: to make the world more beautiful, or to defend your independence?

Yes

No

23. What would you prefer to read: (1) an interesting educative book of the sphere, which is not your major or (2) a book specifying the knowledge in your major?

1

24. If you felt that your family needs more money, would you rather take up a profession that would bring more revenue, instead of the one, where you fulfil yourself as a professional, and a personality?

Yes

No

25. What is more important for you: to have people around you that would be (1) aesthetic, and beautiful, or (2) just kind and friendly, even if their appearances are absolutely inelegant?

26. Which of the two projects would you prefer: (1) the one, which has more public importance, and is difficult to implement, or (2) the one that will make the world aesthetically more perfect?

2

27. What is best: (1) to achieve a more meaningful result of work together with your colleagues, or (2) to work in a project, which is more modest in terms of scale, and aimed at your personal success? 1

28. What is more important: to participate in a large-scale project (1) in a role, which is unusual, and not comfortable for you, or spend the same time to achieve (2) a more modest, but your own desired goal? 1

2

29. What is more important for you: to be a manager (1) without any considerable financial income or you prefer to have material wealth (2) without having a right to solve meaningful issues?

2

30. Is the Internet for you, first of all, the opportunity to find new information (1) or for you it is more important to have the possibility to communicate (2) in it?

1

2

31. What would you choose: play the main part in a good film (1) provided you are required to gain considerable extra weight, or to play a minor role (2) without gaining weight? 1

32. Any success implies business trips, much work and fewer opportunities for communication. Are you ready to generally pay for your success by means of losing a greater part of your circle of contacts? YES NO

33. What is more important for you: elegance and style (1) of an acquaintance you have met, or just an opportunity to talk to them about your subject of concern (2)? 1

34. What kind of business is more acceptable to you: to be engaged in reselling large consignments of everyday clothes for 
broad layers of population and get a great stable profit, or to sell limited consignments of elegant aesthetic clothes? 1 2

35 . Would you agree not to have voting rights when dealing with the important issues if you got good money for that (1) or it's better to remain in middle financial conditions and to maintain your independence (2)?

1

2

36. Is it better to get an average salary as a programmer in a common company (1), or to create new software while getting a more modest financial reward?

1

37. What is more attractive: (1) to be successful and well-known for mass media, or (2) to work in the government agencies? 1

2

38. You are a project manager. Should you entrust your subordinates with all the tasks (1) because management is a responsible thing by itself, or would you like to make a part of the project (2) with your own hands?

39. Is it important for you to work for a famous and successful company (1) at a prestigious position, or if you get the same amount of financial reward, you could work in any company (2) that allowed you to do what you like most? 1

40. Do you think that you spend enough time with your children (1) and it's better to devote your time to a worthy achievement (project, outcome), or do you believe you spend enough time working on your project and it's more important (2) to spend more time with your children? 1

2

41. What's more appropriate for you: to constantly search for new knowledge, or for the time to spend with your family? 2

42. If you feel pressure from your friends, then (1) you communicate less with them, or (2) everything remains as it is? 1

2

43. What is more important: to buy a personal website in order to find people, who are engaged in (1) the same business (profession), or in order to widen your circle of contacts (2) in all your hobbies? 1

44. What do you more feel up to: to implement a project (1) without going into all aspects of it, or to understand all its aspects and to implement it at a later date (2)?

2

45. You love your parents but they still want to interfere in your life. Are you ready to express your affection to them by fulfilling many of their (1) wishes or you will communicate less with them (2) until they stop interfering in your affairs? 1

46. What is more important: to show your boss that you are able to make decisions (1) and make him angry again, or to agree to lose a part of your independence (2) for the sake of your own peace of mind?

47. What function in making clothes would you prefer: (1) to develop a new design, or (2) to control other people in the sales process? 1

\section{Result}

Rating Scoring Technique in Motivational Testing. A rating system was used for assessing the motive significance. In this system the motive rating was higher if it had been more often chosen in the paired comparison with all other motives.

This can be demonstrated by using a trivial example. Suppose you answer 10 questions, in which the material motive material is opposed to the motive of power. And in 6 cases out of 10 you prefer the material motive. Let us assign a rating of 2,000 to the motive of power. Then the material motive will be equal to $2,000+(6-4) \times 1,000 /(6+4)=2,200$.
The rating difference of 200 points gives the advantage of 2 "extra" advantage points to the "material" motive. Now, suppose, we are comparing the motive of power and the motive of achievement. We obtain a ratio of 7:3 in favour of the motive of power. In this case, since its rating is fixed at 2,000 , we obtain the rating of the motive of achievement as $2,000+(3-7) \times 1,000 /(3+7)=1,600$. Hence, we obtained the following ratings for one person: material motive $-2,200$, motive of power $-2,000$, motive of achievement $-1,600$. It means that in case there will be 10 questions concerning the correlation of the material motive and the motive of achievement, we are expecting that the former will get an advantage of 8 to 2 , since in this case the difference will be 
600 points. But if we know the answer beforehand, why do we need to ask "extra" questions? Using a rating system allows to minimize a number of questions, and to widen a range of motives in question due to this fact. If you take 10 motives and want to arrange them with respect to one another, then while comparing the answers to 10 questions in pairs, you should ask 550 questions. None of the respondents will endure such a test and will either begin to answer "at a venture" or refuse to answer at all. Hence, the range of the studied motives will have to be reduced to 3 or 4 of them. Rating allows you find a way out of the situation, in our case leaving 11 motives and 47 questions. Rating allows you to solve the problem that will inevitably arise if the respondent would not want to answer a certain question. Rating allows to combine the results of one experiment with those of another provided the common motives are available. There were two experiments in our example but the material motive was involved in both of them. The final distribution of motives according to the ratings will be carried out due to this fact and due to the usage of rating. Such thing is impossible to do in a typical scoring system in heteromorphic experiments. Let us show how we obtain a system of linear equations using a practical example.

Table 2. Example of distributing the answers according to motives.

\begin{tabular}{llllll}
\hline Motive & $\mathbf{1}$ & $\mathbf{2}$ & $\mathbf{3}$ & \\
\hline A. Material & & $6: 4$ & $7: 3$ & $13: 7$ & Rt \\
B. Of power & $4: 6$ & & $6: 4$ & 2200 & $10: 10$ \\
C. Of Achievement & $3: 7$ & $4: 6$ & & $7: 13$ & 2000 \\
\hline
\end{tabular}

$$
\left\{\begin{array}{c}
\operatorname{Rt}(A)=\left(\frac{6+4}{13+7}\right) \times \operatorname{Rt}(B)+\left(\frac{7+3}{13+7}\right) \times \operatorname{Rt}(C)+\frac{13-7}{13+7} \times 1000 \\
\operatorname{Rt}(B)=\left(\frac{6+4}{10+10}\right) \times \operatorname{Rt}(A)+\left(\frac{4-6}{10+10}\right) \times \operatorname{Rt}(C)+\frac{10-10}{10+10} \times 1000 \\
\operatorname{Rt}(C)=\left(\frac{7+3}{7+13}\right) \times \operatorname{Rt}(A)+\left(\frac{6+4}{7+13}\right) \times \operatorname{Rt}(B)+\frac{7-13}{7+13} \times 1000 \\
(\operatorname{Rt}(A)+\operatorname{Rt}(B)+\operatorname{Rt}(C)) / 3=2000
\end{array}\right.
$$

Having obtained the Rt value for motives 1 and 2 for the given respondent $i$, it is possible to assess the possibility of their choice in pair-wise comparison.

$$
\mathrm{P}=(1000+(\operatorname{Rti}(1)-\operatorname{Rti}(2))) / 2000
$$

\section{Discussion}

PRACTICAL EXAMPLE: Would you remain a Chief Executive Officer of the local branch of a company with the relative independence in decision-making or would you agree to a higher, but subordinate position in a more well-known company, without the usual autonomy? Would you sacrifice your independence for a more successful career? The motive of independence is opposed to the motive of success.

Suppose that Rt (independence) $=2,000:$ Rt (success) $=$ 2,500

$\mathrm{P}($ independence $)=0,5+((2,000-2,500) / 2,000)=0,5-0,25$ $=0,25$. In the present situation, the likelihood that a person will strive to maintain their independence is 0.25 , while the chance of selecting the option with the motivation of success is 0.75 .

\begin{tabular}{|c|c|c|c|c|c|c|c|c|c|c|c|c|}
\hline & Motives & 1 & 2 & 3 & 4 & 5 & 6 & 7 & 8 & 9 & 10 & 11 \\
\hline 1 & Knowledge & & 1 & 1 & 1 & 1 & 1 & 1 & 1 & & & 1 \\
\hline 2 & Negative & 1 & & 1 & 1 & & 1 & 2 & 1 & 1 & 1 & 1 \\
\hline 3 & Communication & 1 & 1 & & 1 & 1 & & & 1 & 1 & 1 & 1 \\
\hline 4 & Material & 1 & 1 & 1 & & 1 & 1 & 1 & & 1 & 1 & 1 \\
\hline 5 & Success & 1 & & 1 & 1 & & 1 & 1 & 1 & 1 & 1 & 1 \\
\hline 6 & Authorities & 1 & 1 & & 1 & 1 & & & 1 & 1 & & 1 \\
\hline 7 & Humanistic & 1 & 2 & & 1 & 1 & & & 1 & 1 & 1 & 1 \\
\hline 9 & Aesthetic & & 1 & 1 & 1 & 1 & 1 & 1 & & & 1 & 1 \\
\hline 10 & Independence & & 1 & 1 & 1 & 1 & & 1 & 1 & 1 & & 1 \\
\hline 11 & Progress & 1 & 1 & 1 & 1 & 1 & 1 & 1 & 1 & 1 & 1 & \\
\hline
\end{tabular}

Table 3. Matrix of the distribution of competing motifs in the test.

We show the first equation in the system of linear equations for the motive of knowledge. This motif is involved in 8 questions. Therefore, the share of each of the answers will be $1 / 8$. The location of the motive is determined by the free term of the equation. It displays the number of responses in support of this motive. With a balance of 2: 8 (two answers in support of the motive of cognition and 8 in support of other motives), the final equation in the system of linear equations of the motive of cognition will look like this:

$$
\begin{gathered}
\operatorname{Rt}(1)-(1 / 8) \times \operatorname{Rt}(2)-(1 / 8) \times \operatorname{Rt}(3)-(1 / 8) \times \operatorname{Rt}(4)-(1 / 8) \times \operatorname{Rt}(5)-(1 / 8) \times \operatorname{Rt}(6)-(1 / 8) \times \operatorname{Rt}(7)-(1 / 8) \times \operatorname{Rt}(8)-(1 / 8) \times \operatorname{Rt}(11) \\
=1000 \times(2-8) /(2+8)
\end{gathered}
$$


For each of the 11 motives, a similar equation will be written. And 12 more equations will be given the average rating of all 11 motives.

The rating motivation test was created by A. A. Polozov,
Doctor of Education, in 2010. After a month, the test-retest reliability factor during the survey made on 110 students of Ural Federal University was 0.81 .

Table 4. Coefficients for solving a system of linear equations.

\begin{tabular}{|c|c|c|c|c|c|c|c|c|c|c|c|c|}
\hline & 1 & 2 & 3 & 4 & 5 & 6 & 7 & 8 & 9 & 10 & 11 & \\
\hline 1 & 1,000 & $-0,125$ & $-0,125$ & $-0,125$ & $-0,125$ & $-0,125$ & $-0,125$ & $-0,125$ & 0,000 & 0,000 & $-0,125$ & 250 \\
\hline 2 & $-0,100$ & 1,000 & $-0,100$ & $-0,100$ & 0,000 & $-0,100$ & $-0,200$ & $-0,100$ & $-0,100$ & $-0,100$ & $-0,100$ & 0 \\
\hline 3 & $-0,125$ & $-0,125$ & 1,000 & $-0,125$ & $-0,125$ & 0,000 & 0,000 & $-0,125$ & $-0,125$ & $-0,125$ & $-0,125$ & 500 \\
\hline 4 & $-0,111$ & $-0,111$ & $-0,111$ & 1,000 & $-0,111$ & $-0,111$ & $-0,111$ & 0,000 & $-0,111$ & $-0,111$ & $-0,111$ & 333 \\
\hline 5 & $-0,111$ & 0,000 & $-0,111$ & $-0,111$ & 1,000 & $-0,111$ & $-0,111$ & $-0,111$ & $-0,111$ & $-0,111$ & $-0,111$ & -556 \\
\hline 6 & $-0,143$ & $-0,143$ & 0,000 & $-0,143$ & $-0,143$ & 1,000 & 0,000 & $-0,143$ & $-0,143$ & 0,000 & $-0,143$ & -143 \\
\hline 8 & $-0,125$ & $-0,125$ & $-0,125$ & 0,000 & $-0,125$ & $-0,125$ & $-0,125$ & 1,000 & 0,000 & $-0,125$ & $-0,125$ & 250 \\
\hline 9 & 0,000 & $-0,125$ & $-0,125$ & $-0,125$ & $-0,125$ & $-0,125$ & $-0,125$ & 0,000 & 1,000 & $-0,125$ & $-0,125$ & -500 \\
\hline 10 & 0,000 & $-0,125$ & $-0,125$ & $-0,125$ & $-0,125$ & 0,000 & $-0,125$ & $-0,125$ & $-0,125$ & 1,000 & $-0,125$ & -250 \\
\hline 11 & 0,091 & 0,091 & 0,091 & 0,091 & 0,091 & 0,091 & 0,091 & 0,091 & 0,091 & 0,091 & 0,091 & 2200 \\
\hline
\end{tabular}

The table contains the values of the coefficients $a(i, j)$ and $b$ (i) for solving a system of linear equations. Numbers 1-11 are numbers of motives. The values of $b(i)$ are given in the last column. They are taken from a practical example. For example, if the motive of knowledge received an advantage 5 times and was ignored 3 times, then the value $b(1)=1000 \times$ $(5-3) /(5+3)=250$.

Now we get the values of Rt (i) of each of the motives. Their average value is equal to 2200 . In our career guidance test there are 4 indicators that correspond to the motives of remuneration, self-realization, power and achievement. We obtain the average value of the rating of these motifs - Rtcp. We also consider that the sum of the values of the coefficients should be equal to one. Then the value of each of the coefficients will be determined by the formula: $\delta=(1000+(\mathrm{Rt}$ (i) -Rtcp)) / 4000

As a result, we received an individual assessment of the significance for the entrant of a given profession or specialty. This opportunity is used by us in the test of the vocational guidance center of our university.

\section{Conclusions}

11 motives, which do not have mutual correlations, and are independent from one another, were chosen from a variety of motives mentioned in the existing literature. We did not take the basic motives into account, such as the need for security, or A. Maslow's physiological motives, because they are more significant for any person, and therefore are of no interest for the research. In everyday life we are interested not in the motives as such, but in the choice to be made by each of us in any given situation under the influence of these motives. Therefore, a test is suggested where the respondent chooses from two alternatives that contain opposing motives. A rating system was used for assessing the motive significance. In this system the motive rating was higher if it had been more often chosen in the paired comparison with all other motives. The difference in ratings of the two motives is linearly connected with the possibility of selecting both motives. As a result of the work done, we can predict the behaviour of any respondent, and tell what they will choose in a particular life situation if it can be interpreted as an opposition of two motives.

Disadvantages of the existing motivation testing techniques are the following:

1. minimum number of the motives being studied;

2. absence of a real-life choice situation

3. scoring system: a points-based system is used. A person gets a certain score for each motive. Here the motives do not contradict each other, as it happens in real life. In this case the respondent can increase their ratings on all scales in multi-component techniques for motivation determination.

4. desire to give not a real rating but the one, which would be approved by others

5. the obtained numbers do not have any physical meaning. The advantages of the given technique are the following:

1. Possibility to simultaneously compare 11 motives that have no correlations with one another.

2. Possibility to further widen the number of motives being compared.

3. Pair-wise comparison of motives with the most common situations of choice, competitive model of testing

4. Minimization of a number of questions from 550 to 47 due to the use of rating assessment, and, as a result of it, a higher degree of adequacy of answers to the questions, a higher test-retest reliability.

5. Possibility to transform the obtained ratings into the likelihood of choosing one of two alternatives in the real life situation.

6. Possibility to distinguish the dominating motives of the respondent.

7. Maximum degree of the test's visibility for the respondent.

8. Absence of less profitable or negative option among the answers, and, as a result, a higher credibility of the answers. 


\section{References}

[1] Talanov V. L., Malkina-Pykh I. G. Handbook of Practical Psychologist $\backslash$ SPb.: Sova, Moscow: EKSMO, 2002. - 928 p.

[2] Heckhausen H. Motivation and Action. Vol. 1-2. - Moscow. 1986.

[3] Ilyin E. P. Motivation and Motives. - Saint Petersburg. - 2006.

[4] Ilyin E. P. The Essence and Structure of a Motive // Psychological Journal. -1995. - Iss. 2.

[5] Polozov A. A., Skoryh S. A. Evaluation of a Motivational Model of People with Different Personality and Character Types / Sport Psychologist, Iss. 1, 2012, Moscow.

[6] Leontiev D. A. Systemic and Semantic Nature and Functions of a Motive // MSU Bulletin.-1993. - Iss.

[7] Maslow A. Motivation and Personality. - Moscow. - 1998.

[8] Psychological Structure Modules in Sport / A. A. Polozov, N. N. Polozova / Moscow: Sovetsky Sport Publishing House, 2009, 380 p.

[9] Milman V. E. Internal and External Motivation of Learning Activity // Issues of Psychology. - 1987. - Iss. 5.

[10] Richard M. Ryan. Intrinsic and Extrinsic Motivations: Classic Definitions and New Directions/ Contemporary Educational
Psychology/Volume 25, Issue 1, January 2000, Pages 54-67.

[11] Human Motivation/David C. McClelland/ CUP Archive, 1987. $663 \mathrm{p}$.

[12] Magomed-Eminov M. Sh. Achievement Motivation: Structure and Mechanisms: Synopsis of a Thesis for... Candidate of Psychological Sciences. - Moscow, 1987.

[13] Magomed-Eminov M. Sh. Psychodiagnostics of Motivation // General Psychodiagnostics. - Moscow, 1998.

[14] A Study on the Achievement Motivation. Methodical manual. Compiled by B. G. Rebzuev, Acad. Ed. V. N. Panferov. - Saint Petersburg. - 1993.

[15] Human Motivation /B. Weiner/ Springer Science \& Business Media, 2012. - p. 480.

[16] Ulitova E. S. Motivational Analysis of a Person's Behaviour over Time: Synopsis of a Thesis for... Candidate of Psychological Sciences. - Moscow, 1988.

[17] Martsinkovskaya T. D. History of Psychology. - Moscow. 2001.

[18] Dodonov B. I. Structure and Dynamics of Motives of Activity // Issues of Psychology. - 1984. - Iss. 4.

[19] Polozov A. A. Psychological Portraits of Sport Club Staff // Sport Psychologist, Iss. 3 (6), 2005. Ratings and Rankings in Sports: Past, Present, and Future / A. A. Polozov / Sovetsky Sport Publishing House, 2007. 310 p. 